\title{
Comprehensive characterization of natural organic matter by MALDI- and ESI-Fourier transform ion cyclotron resonance mass spectrometry
}

\author{
Dong Cao ${ }^{\mathrm{a}, 1}$, Huogao Huang ${ }^{\mathrm{b}, 1}$, Ming Hu ${ }^{\mathrm{c}, 1}$, Lin Cui ${ }^{\mathrm{a}}$, Fanglan Geng ${ }^{\mathrm{a}}$, Ziyu Rao ${ }^{\mathrm{a}}$, \\ Hongyun Niu ${ }^{a}$, Yaqi Cai ${ }^{a}$, Yuehui Kang ${ }^{a, *}$ \\ a State Key Laboratory of Environmental Chemistry and Ecotoxicology, Research Center for Eco-Environmental Science, Chinese Academy of Sciences, P.O. \\ Box 2871, 18 Shuangqing Road, Haidian District, Beijing 100085, China \\ ${ }^{\mathrm{b}}$ Department of Endocrinology and Rheumatology, Navy General Hospital, PLA, 6 Fucheng Road, Haidian District, Beijing 100048, China \\ c Central Lab Navy General Hospital, PLA, 6 Fucheng Road, Haidian District, Beijing 100048, China
}

\section{H I G H L I G H T S}

- MALDI-FT-ICR-MS was firstly employed for molecular characterization of NOM.

- 1,8-Bis(dimethyl-amino)-naphthalene (DMAN) was used as matrix.

- Mass spectra of NOM generated by MALDI and ESI methods were compared.

- Complementary molecular information of NOM was provided by MALDI.

\section{A R T I C L E I N F O}

\section{Article history:}

Received 15 November 2014

Received in revised form 26 January 2015

Accepted 28 January 2015

Available online 7 February 2015

\section{Keywords:}

Natural organic matter

Fourier transform ion cyclotron resonance mass spectrometry

Matrix assisted laser desorption/ionization

Molecular characterization
G R A P H I C A L A B S T R A C T

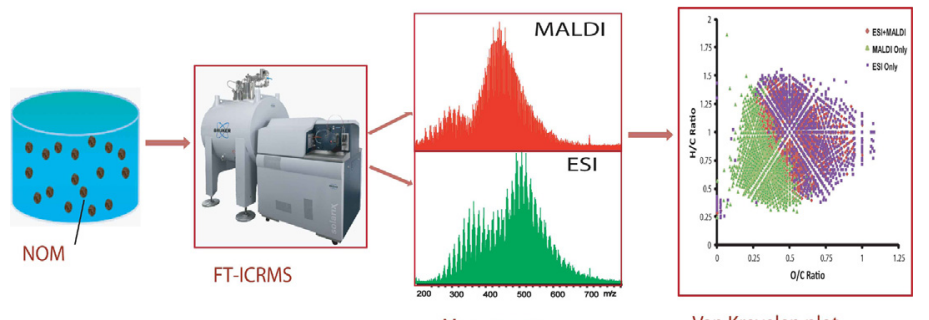

Van Krevelen plot 
special groups which are liable to absorb electron from other molecules to generate free radical anions during MALDI ionization.

(c) 2015 Elsevier B.V. All rights reserved.

\section{Introduction}

Natural organic matter (NOM) is a complex and poorly defined organic mixture present in the environment. Many studies have reported that NOM may affect the toxicity of nanoparticles by forming NOM-nanoparticle composites [1], may interact with inorganic contaminant in the environment to affect its environmental behavior [2], and may be a source of new contaminants during the chlorination processes of drinking water [3,4]. Because NOM molecules play a pivotal role in the cycling and transport of elements in the ecosphere and have other effects on the environmental quality, it is important for environmental chemists to better understand the molecular composition and transformation of NOM.

However, due to its complexity and special properties, it is difficult to separate NOM using chromatographic methods. As a result, the extent of molecular information about NOM is largely restricted. Fourier transform ion cyclotron resonance mass spectrometry (FT-ICR-MS), due to its ultrahigh resolution and mass accuracy, can provide molecular elemental information about NOM without chromatographic separation [5,6], and has been used for accurate characterization of NOM [7-9]. Electrospray ionization (ESI) is the most commonly used ionization method for FT-ICR-MS characterization of NOM because it is one of the softest ionization methods and can be easily coupled with FT-ICR-MS $[10,11]$. However, during ESI analysis, only some polar and moderately polar molecules of NOM can be ionized by ESI, and most of non-polar compounds cannot be detected [11]. Recently, some reports combined ESI and APPI ionization methods to characterize DOM and compared the obtained mass spectra $[12,13]$. The results suggested that APPI tended to ionize smaller and less polar molecules, whereas ESI produces ions that in general contain more oxygen atoms. Moreover, Hertkorn et al. used different ionization methods (ESI, APCI and APPI) to characterize Suwannee River fulvic acid (SuwFA) [8]. The results indicated that molecules with lower $\mathrm{O} / \mathrm{C}$ ratio were preferentially ionized in the negative APCI mode, and molecules with higher $\mathrm{O} / \mathrm{C}$ ratio were preferentially ionized in the negative ESI and APPI mode. Thus, in order to obtain comprehensive molecular information about NOM, multiple ionization methods should be combined. Laser desorption ionization (LDI) and matrix assisted laser desorption/ionization (MALDI), two other soft ionization methods, are also used for NOM characterization. However, LDI might generate excessive fragmentation of NOM during the ionization process because it is a relatively energetic ionization method $[14,15]$. MALDI, with the addition of external matrices, can facilitate energy dispersion and enhance sample ionization, so this method tends to generate intact molecular ions with minimal or no fragmentation [16,17]. Mugo et al. [17] had tested an array of MALDI matrices for humic substances detection. The results showed that 2,5-dihydroxybenzoic acid (DHBA) was suitable for humic substances detection, because it exhibited superior ionization efficiency, low noise, and few matrix interfering ions at the mass range of interest. Furthermore, the results also indicated that compared with LDI, fragmentation of high-MW ions was minimized by using MALDI because the laser energy was absorbed by the matrix and only partially transferred to the sample during the ionization process [17]. However, molecular elemental information about humic substance was not obtained by Mugo's study because a lower resolution mass analyzer was used.
In this study, 1,8-bis(dimethyl-amino)-naphthalene (DMAN) was used as the matrix for molecular-level characterization of NOM with mass range of $200-800$ Da by MALDI-FT-ICR-MS. Meanwhile, a systematically molecular visual comparison of mass spectra generated by MALDI and ESI were performed.

\section{Experimental}

\subsection{Chemicals and samples preparation}

Suwannee River natural organic matter (SuwNOM) was purchased from the International Humic Substances Society. 1,8Bis(dimethyl-amino)-naphthalene (DMAN, $\geq 98 \%$ ) was obtained from Sigma-Aldrich (Steinheim, Germany). Ultra-pure water was prepared using a Milli-Q system (Millipore, Milford, MA, USA). Methanol (HPLC grade) was purchased from Fisher Scientific (Fair Lawn, New Jersey). Other chemicals were analytical grade.

$0.5 \mathrm{mg} \mathrm{mL}^{-1}$ of NOM solution was prepared by dissolving NOM in methanol; DMAN was dissolved in $50 \%$ methanol aqueous solution to form $1 \mathrm{mg} \mathrm{mL}^{-1}$ of matrix solution. For MALDI-FT-ICRMS analysis, $0.5 \mathrm{mg} \mathrm{mL}^{-1}$ of NOM was mixed with $1 \mathrm{mg} \mathrm{mL}^{-1}$ of DMAN matrix at equal volumes, and then the solution was vortexed for $20 \mathrm{~s}$ at room temperature. Subsequently, $1 \mu \mathrm{L}$ of the final solution was directly spotted on a 384-well MALDI target plate (AnchorChip ${ }^{\mathrm{TM}}$ target plate, provided by Bruker Daltonics, Germany), followed by drying at room temperature for MALDI-FTICR-MS analysis. For ESI-FT-ICR-MS analysis, $0.25 \mathrm{mg} \mathrm{mL}^{-1}$ of NOM methanol solution was directly infused into the ESI source unit at a flow rate of $120 \mu \mathrm{Lh}^{-1}$.

\subsection{Instrumentation}

Ultrahigh resolution mass spectra were acquired using a Bruker SolariX Fourier transform ion cyclotron resonance mass spectrometer (FT-ICR-MS) equipped with a $15.0 \mathrm{~T}$ superconducting magnet and a dual-mode ESI/MALDI ion source. For ESI analysis, samples were continuously infused into the ESI unit by syringe infusion at a flow rate of $120 \mu \mathrm{Lh}^{-1}$. ESI needle voltage was set to $-3.8 \mathrm{kV}$. For MALDI analysis, samples spotted on the target plate were irritated by a $355 \mathrm{~nm}$ and $1000 \mathrm{~Hz}$ solid-state Smartbeam Nd:YAG UV laser, and laser power was set at 20\%. 100 laser shots were summed for each mass spectrum. All samples were analyzed in negative ionization mode with broadband detection. Ions were accumulated in a hexapol ion trap for $2.0 \mathrm{~s}$ before being introduced into the ICR cell. $4 \mathrm{M}$ words of data were recorded per broadband mass scan. The lower mass limit was set to $m / z=200 \mathrm{Da}$, the upper mass limit was set to $m / z=1500 \mathrm{Da}$. 20 mass spectra were averaged per sample. The spectra were externally calibrated with $10 \mathrm{mM}$ of sodium formate solution in $50 \%$ isopropyl alcohol using a linear calibration, and then internally recalibrated using an in-house reference mass list. After internal calibration the mass error was less than $500 \mathrm{ppb}$ over the entire mass range. Peaks were identified with Bruker Data Analysis software.

\subsection{Molecular formula assignment}

All possible formulas were calculated with Formula Calculator software based on the requirement that the mass error between the measured mass, and the calculated mass for a given chemical 
formula is less than $0.5 \mathrm{ppm}$, and the signal-to-noise ratio $(\mathrm{S} / \mathrm{N})$ of mass peaks exceeds 5 . Because NOM mainly contains $\mathrm{C}, \mathrm{H}$, and $\mathrm{O}$ elements, whereas N, P and S elements are found in a lower level [18], in the present work, only $\mathrm{C}, \mathrm{H}$, and $\mathrm{O}$ elements were considered in the calculation: ${ }^{12} \mathrm{C}(1-100),{ }^{1} \mathrm{H}(1-200),{ }^{16} \mathrm{O}(0-50)$, and ${ }^{13} \mathrm{C}(0-1)$. The elemental ratios of $\mathrm{H} / \mathrm{C}<2.0$ and $\mathrm{O} / \mathrm{C}<1.2$ were used as further restrictions for formula calculation. Once formulas had been assigned, the obtained mass lists were transformed into Excel format and divided into different categories for interpretation.

For visually graphic displays of the mass spectral data, the following parameters were calculated according to the previous reports: $\mathrm{H} / \mathrm{C}$ ratio and $\mathrm{O} / \mathrm{C}$ ratio, parameters for constructing Van Krevelen diagram [19]; Kendrick mass (KM) and Kendrick mass defect (KMD) for the purpose of identifying $\mathrm{CH}_{2^{-}}, \mathrm{CO}_{2^{-}}, \mathrm{O}-, \mathrm{CO}$, $\mathrm{H}_{2} \mathrm{O}$-, and $\mathrm{H}_{2}$-homologous molecular formulas series [7,20]; the modified aromaticity index (AI_mod) was calculated to estimate the fraction of aromatic and condensed aromatic structures [9,18]; the nominal oxidation state of carbon (NOSC) was calculated from the formulas to indirectly show the polarity of NOM constituents detected by FT-ICR-MS [9].

\section{Results and discussions}

DMAN is a classic "proton sponge" compound which was introduced by Alder et al. [21], and was used as the matrix for fatty acids detection and metabolomics studies by MALDI-MS [22,23]. Recently, DMAN was also applied as the matrix for perfluorinated acidic compounds detection by our group [24,25]. The primary advantage of a DMAN matrix is that it has no matrix ion interference in low mass region, and it is well-suited for detection of small acidic compounds. Because the primary constituents of NOM are acidic compounds, DMAN should be an ideal matrix for NOM characterization by MALDI-FT-ICR-MS. The details about optimizing analytical variables of DMAN matrix, such as concentration, solvent composition and laser energy, will be discussed in another manuscript being prepared by our group. In this paper, we mainly focus on the molecular elemental information about NOM provided by MALDI-FT-ICR-MS.

The mass spectra of NOM detected separately by MALDI- and ESI-FT-ICR-MS are displayed in Fig. 1. It is evident that the data followed an approximately Gaussian distribution, which was a remarkable feature of FT-ICR mass spectra of NOM widely reported in previous studies $[20,26,27]$, and compound detection was exhibited in both mass spectra within the 200 to $800 \mathrm{~m} / z$ range (shown in Fig. 1 A and B). Over 8300 peaks with signal-to-noise of 5 or greater were detected by MALDI-FT-ICR-MS. However, in ESI negative mode, only about 6800 peaks were detected. The peak resolving power was calculated to be over 400000 at $\mathrm{m} / z 400$. Fig. 1C and D separately displayed the scale-expanded segment at nominal $\mathrm{m} / \mathrm{z} 447$ in each spectrum. In the $\mathrm{m} / \mathrm{z}$ range from 447.0000 to 447.3000 , only 10 peaks assigned molecular formulas were detected by ESI, but with MALDI, 17 assignable molecular formulas were observed. The molecular formulas that could be identified by MALDI and ESI were annotated with black, while the molecular formulas that could be identified by MALDI or ESI were annotated with blue or red, respectively (Fig. 1C and D). All proposed molecular formulas at nominal $\mathrm{m} / \mathrm{z} 447$ are listed in Table 1. It shows that the commonly identified molecules contain carbon, oxygen, and hydrogen compounds ranging from $\mathrm{C} 16$ to $\mathrm{C} 24, \mathrm{O} 8$ to $\mathrm{O} 15$, and $\mathrm{H} 12$ to $\mathrm{H} 32$, whereas for unique identified molecules, the elemental contents varied from C23 to C29, 05 to O10, H12 to H36 for MALDI, and C17 to C19, O20 to O28, H12 to H14 for ESI. This result suggests that constituents of NOM with lower $\mathrm{O} / \mathrm{C}$ ratio are preferentially ionized in MALDI negative mode, whereas in ESI negative mode, constituents of NOM with higher O/ $C$ ratio (as compared with MALDI uniquely identified compounds) are preferentially ionized. The selectivity of ESI in negative mode for NOM observed in our work coincides with a previous study reported by Hertkorn et al. [8].

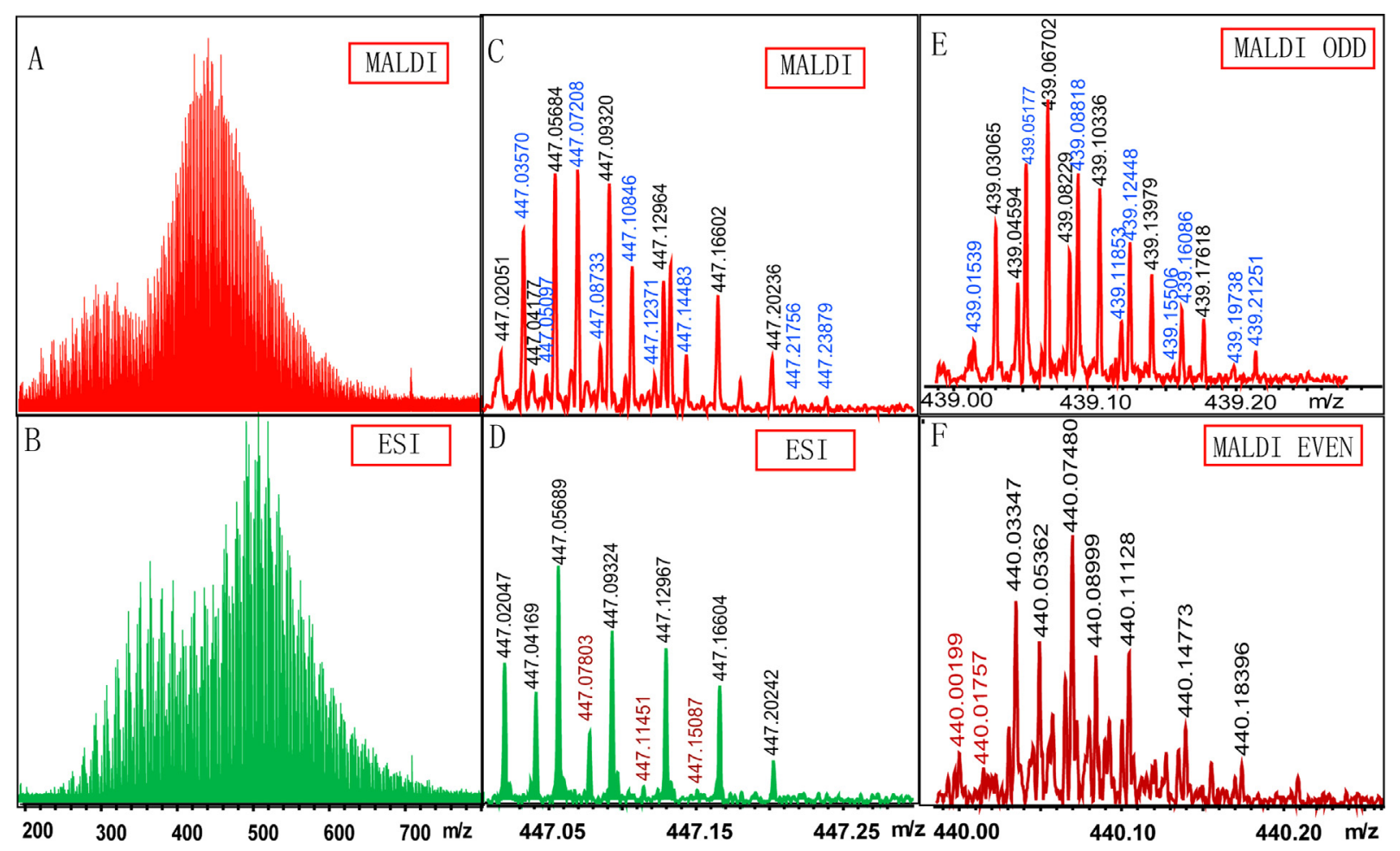

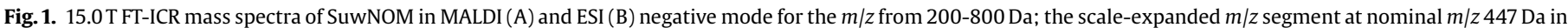

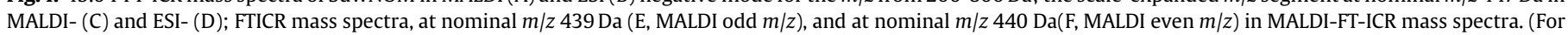
interpretation of the references to color in the text, the reader is referred to the web version of this article.) 
Table 1

$\mathrm{C}_{n} \mathrm{H}_{m} \mathrm{O}_{q}$ identified by MALDI- and ESI-FT-ICR-MS.

\begin{tabular}{|c|c|c|c|c|c|c|c|}
\hline \multicolumn{4}{|l|}{ MALDI } & \multicolumn{4}{|l|}{ ESI } \\
\hline Measured $m / z$ & Calculated $\mathrm{m} / \mathrm{z}$ & Error (ppm) & Proposed molecular formula & Measured $m / z$ & Calculated $\mathrm{m} / \mathrm{z}$ & Error (ppm) & Proposed molecular formula \\
\hline 447.02051 & 447.02051 & 0 & C19H12 013 & 447.02047 & 447.02051 & -0.08 & C19H12 013 \\
\hline 447.04177 & 447.04164 & 0.29 & C16H16 015 & 447.04169 & 447.04164 & 0.11 & C16H16 015 \\
\hline 447.05684 & 447.0569 & -0.13 & С20H16 012 & 447.05689 & 447.0569 & -0.02 & С20H16012 \\
\hline 447.09320 & 447.09328 & -0.17 & С21H20 011 & 447.09324 & 447.09328 & -0.08 & C21H20 011 \\
\hline 447.12964 & 447.12967 & -0.06 & C22H24 010 & 447.12967 & 447.12967 & 0 & $\mathrm{C} 22 \mathrm{H} 24010$ \\
\hline 447.16602 & 447.16605 & -0.06 & С23H28 09 & 447.16604 & 447.16605 & -0.02 & C23H28 09 \\
\hline 447.20236 & 447.20244 & -0.17 & C24H32 08 & 447.20242 & 447.20244 & -0.04 & C24H32O8 \\
\hline 447.03570 & 447.03570 & 0 & $\mathrm{C} 23 \mathrm{H} 12 \mathrm{O} 10$ & 447.07803 & 447.07802 & 0.02 & C17H20014 \\
\hline 447.05097 & 447.05102 & -0.11 & $\mathrm{C} 27 \mathrm{H} 12 \mathrm{O} 7$ & 447.11451 & 447.11441 & 0.22 & $\mathrm{C} 18 \mathrm{H} 24 \mathrm{O} 13$ \\
\hline 447.07208 & 447.07215 & -0.15 & C24H16O9 & 447.15087 & 447.1508 & 0.15 & $\mathrm{C} 19 \mathrm{H} 28 \mathrm{O} 12$ \\
\hline 447.08733 & 447.08741 & -0.17 & C28H16 O6 & & & & \\
\hline 447.10846 & 447.10854 & -0.17 & $\mathrm{C} 25 \mathrm{H} 20 \mathrm{O} 8$ & & & & \\
\hline 447.12371 & 447.12379 & -0.17 & $\mathrm{C} 29 \mathrm{H} 20 \mathrm{O} 5$ & & & & \\
\hline 447.14483 & 447.14492 & -0.20 & $\mathrm{C} 26 \mathrm{H} 24 \mathrm{O}$ & & & & \\
\hline 447.18115 & 447.18131 & -0.35 & C27H28O6 & & & & \\
\hline 447.21756 & 447.21769 & 0.29 & $\mathrm{C} 28 \mathrm{H} 32 \mathrm{O} 5$ & & & & \\
\hline 447.23879 & 447.23882 & 0.08 & $\mathrm{C} 25 \mathrm{H} 36 \mathrm{O}$ & & & & \\
\hline
\end{tabular}

Note: Proposed molecular formulas denoted with boldface letters representing the molecules commonly identified by ESI and MALDI.

On the other hand, because in most cases the majority of peaks at even $\mathrm{m} / \mathrm{z}$ are assigned to the ${ }^{13} \mathrm{C}$ isotope of peaks in high resolution mass spectra of NOM, only peaks at odd $\mathrm{m} / \mathrm{z}$ were considered for CHO-molecular formulas assignment in the previous studies [5,19]. However, interestingly, during processing mass spectra in MALDI negative mode in our study, a significant portion of peaks at even $\mathrm{m} / \mathrm{z}$ can also be assigned as $\mathrm{CHO}-$ molecules except for the ${ }^{13} \mathrm{C}$ isotope peaks. Furthermore,

Table 2

$\mathrm{C}_{n} \mathrm{H}_{m} \mathrm{O}_{q}$ identified by MALDI-FT-ICR-MS. (For interpretation of the references to color in the text, the reader is referred to the web version of this article.)

MALDI Odd

\begin{tabular}{|c|c|c|c|c|c|}
\hline $\begin{array}{c}\text { Measured } \\
\mathbf{m} / \mathbf{z}\end{array}$ & $\begin{array}{c}\text { Proposed Molecular } \\
\text { formula }\end{array}$ & $\begin{array}{c}\text { Measured } \\
\mathbf{m} / \mathbf{z}\end{array}$ & $\begin{array}{c}\text { Proposed Molecular } \\
\text { formula }\end{array}$ & $\begin{array}{l}\ddot{\text { mm }} \\
\text { (Da) }\end{array}$ & $\begin{array}{c}\text { Average Äm } \\
(\mathrm{Da}, \mathbf{n}=7)\end{array}$ \\
\hline 439.03065 & C21 H12 011 & 440.03847 & C21 H12 O11 & 1.00782 & \\
\hline 439.04594 & C25 H12 O8 & 440.05362 & C25 H12 O8 & 1.00768 & \\
\hline 439.06702 & C22 H16 O10 & 440.07480 & C22 H16 O10 & 1.00788 & \\
\hline 439.08229 & С26 H16 O7 & 440.08999 & C26 H16 O7 & 1.00770 & 1.00782 \\
\hline 439.10336 & C23 H20 O9 & 440.11128 & C23 H20 O9 & 1.00792 & \\
\hline 439.13979 & C24 H24 O8 & 440.14773 & C24 H24 O8 & 1.00794 & \\
\hline 439.17618 & C25 H28 O7 & 440.18396 & C25 H28 O7 & 1.00778 & \\
\hline 439.01539 & C17 H12 O14 & 440.00199 & C20 H8 O12 & & \\
\hline 439.05177 & C18 H16 O13 & 440.01757 & C24 H8 O9 & & \\
\hline 439.08818 & C19 H20 O12 & & & & \\
\hline 439.11853 & C27 H20 O6 & & & & \\
\hline 439.12448 & C20 H24 O11 & & & & \\
\hline 439.15506 & $\mathrm{C} 28 \mathrm{H} 24 \mathrm{O} 5$ & & & & \\
\hline 439.16086 & C21 H28 O10 & & & & \\
\hline 439.19738 & C22 H32 O9 & & & & \\
\hline 439.21251 & C26 H32 O6 & & & & \\
\hline
\end{tabular}

\section{MALDI Even}


Table 3

Percentages of $\mathrm{C}_{n} \mathrm{H}_{m} \mathrm{O}_{q}$ identified by MALDI- and ESI-FT-ICR-MS.

\begin{tabular}{lclc}
\hline Ionization method & $\begin{array}{l}\text { Number of } \\
\mathrm{C}_{n} \mathrm{H}_{m} \mathrm{O}_{q}\end{array}$ & $\begin{array}{l}\text { Total number of } \\
\mathrm{C}_{n} \mathrm{H}_{m} \mathrm{O}_{q}\end{array}$ & Percent (\%) \\
\hline ESI and MALDI & & & 28.35 \\
ESI Only & 937 & & 35.07 \\
MALDI Only & 1159 & 3305 & 36.58 \\
ESI and MALDI & 1209 & & \\
MALDI even and odd & & 51.50 \\
MALDI odd only & 1271 & 2468 & 4.05 \\
MALDI even only & 100 & & 44.45 \\
MALDI even and & 1097 & & \\
$\quad$ odd & & & \\
\hline
\end{tabular}

compared with the CHO-molecular formulas at odd $\mathrm{m} / \mathrm{z}$, most of the peaks at even $m / z$ have the identical molecular formulas with the peaks at odd $\mathrm{m} / \mathrm{z}$ but have an average difference of 1.00782 between even and odd $m / z$ values. This difference is quite close to the atomic mass of hydrogen (1.007825 Da), so we can deduce that each peak at even $m / z$ having the same molecular formula with that at odd $\mathrm{m} / \mathrm{z}$ is molecular ion $[\mathrm{M}+\mathrm{e}]^{-}$(mass of electron (e) is $0.000549 \mathrm{Da})$, and the corresponding peak at odd $\mathrm{m} / \mathrm{z}$ is deprotonated ion $\left[\mathrm{M}-\mathrm{H}^{+}\right]^{-}$(mass of hydrogen proton $\left(\mathrm{H}^{+}\right)$is $1.007276 \mathrm{Da}$ ). This is a significant finding for NOM characterization. Although for data process simply, radical anions are not wanted, these radical anions can also be well identified due to the ultrahigh resolution of FT-ICR-MS. Meanwhile, these radical anions are beneficial for NOM characterization. Firstly, the proposed molecular formulas assigned by $\left[\mathrm{M}-\mathrm{H}^{+}\right]^{-}$ions at odd $\mathrm{m} / \mathrm{z}$ can be further confirmed by their $[\mathrm{M}+\mathrm{e}]^{-}$ions at even $m / z$; secondly, the molecules being liable to form $[\mathrm{M}+\mathrm{e}]^{-}$ions are very likely to be aromatic or condensed aromatic compounds with special substituent groups which have higher electron affinity and are more likely to absorb electron from other molecules to produce free radical anions during the MALDI ionization process in spite of a matrix being used. Photoexcition and photoionization may be the mechanism for the formation of radical anions [28]. The scaleexpanded segment of mass spectra at nominal $\mathrm{m} / \mathrm{z} 439 \mathrm{Da}$ and $440 \mathrm{Da}$ in MALDI negative mode are displayed in Fig. 1E and F. The blue or red annotations separately represent the unique molecular formulas assigned by MALDI odd or even $\mathrm{m} / \mathrm{z}$ peaks, and the black annotations represent the common formulas assigned by both $\mathrm{m} / \mathrm{z}$ peaks. Table 2 shows the assigned molecular formulas at nominal $m / z 439 \mathrm{Da}$ and $440 \mathrm{Da}$. Molecules shown in green and red progress as follows: as the number of $\mathrm{CH}_{4}$ group increases by one, the number of oxygen atoms decreases by one; molecules noted in green progress from C20 through C26, while molecules noted in red progress from C24 through C28. Through comparison of the proposed molecular formulas, our preliminary conclusion is that for identical classes of molecules, we can state three rules based on the observation that the number of $\mathrm{CH} 4$ and $\mathrm{O}$ groups $(+\mathrm{CH} 4 /-\mathrm{O})$ affect whether a molecule is detected by MALDI at even $m / z$ peaks, odd $\mathrm{m} / \mathrm{z}$ peaks, or both: (1) the molecules with lower $\mathrm{H} / \mathrm{C}$ ratio and higher $\mathrm{O} / \mathrm{C}$ ratio (such as $\mathrm{C}_{20} \mathrm{H}_{8} \mathrm{O}_{12}, \mathrm{C}_{24} \mathrm{H}_{8} \mathrm{O}_{9}$ ) are more likely to form $[\mathrm{M}+\mathrm{e}]^{-}$ions during the MALDI process (only even $\mathrm{m} / \mathrm{z}$ peaks appeared); (2) the molecules with higher $\mathrm{H} / \mathrm{C}$ ratio and lower $\mathrm{O} / \mathrm{C}$ ratio (such as $\mathrm{C}_{26} \mathrm{H}_{32} \mathrm{O}_{6}, \mathrm{C}_{27} \mathrm{H}_{20} \mathrm{O}_{6}, \mathrm{C}_{28} \mathrm{H}_{24} \mathrm{O}_{5}$ ) preferentially form $\left[\mathrm{M}-\mathrm{H}^{+}\right]^{-}$ions during the MALDI process (only odd $\mathrm{m} / \mathrm{z}$ peaks appeared); (3) molecules which fall in between those two extremes may be detected in either odd or even mode. For the class of molecules only observed at odd $\mathrm{m} / \mathrm{z}$ (noted in black on Table 2), no obvious features were observed in CHO-composition, which indicates those molecules may be some special aromatic or condensed aromatic compounds with fewer special substituent groups.

To extend these observations to the whole mass range of detected ions, the data generated by MALDI and ESI were automatically processed with formula assigned software, and different parameters were calculated for visually graphic comparison of the two types of mass spectral data. Collectively, a total of 3305CHO-molecular formulas were assigned for MALDI and ESI negatively odd $\mathrm{m} / \mathrm{z}$ ions in the mass range from 200 to $800 \mathrm{Da}$, of which 1209 (36.58\%) formulas were commonly assigned by both ionization modes (Table 3). The number of unique $\mathrm{CHO}$-molecular formulas assigned by MALDI is 1159 (35.07\%), and only 937 (28.35\%) unique CHO-molecular formulas were assigned by ESI. This result indicates that the MALDI ionization mode can provide molecular information about NOM which ESI cannot detect. Combining different ionization modes (such as MALDI, ESI, APPI and $\mathrm{APCI}$ ) is needed to generate more complete molecular information about NOM. For CHO-molecular formulas assigned by MALDI at odd and even $\mathrm{m} / \mathrm{z}$ peaks, a total of 2468 formulas were assigned by both $m / z$ ions, whereas 1271 (51.50\%) formulas were uniquely observed by MALDI odd $m / z$ ions and only 100 (4.05\%) by MALDI even $m / z$ ions. The number of commonly observed formulas is 1097 (44.45\%) (Table 3). This observation indicates that about half the NOM molecules identified by MALDI may contain special substituent groups which are liable to generate free radical anions.
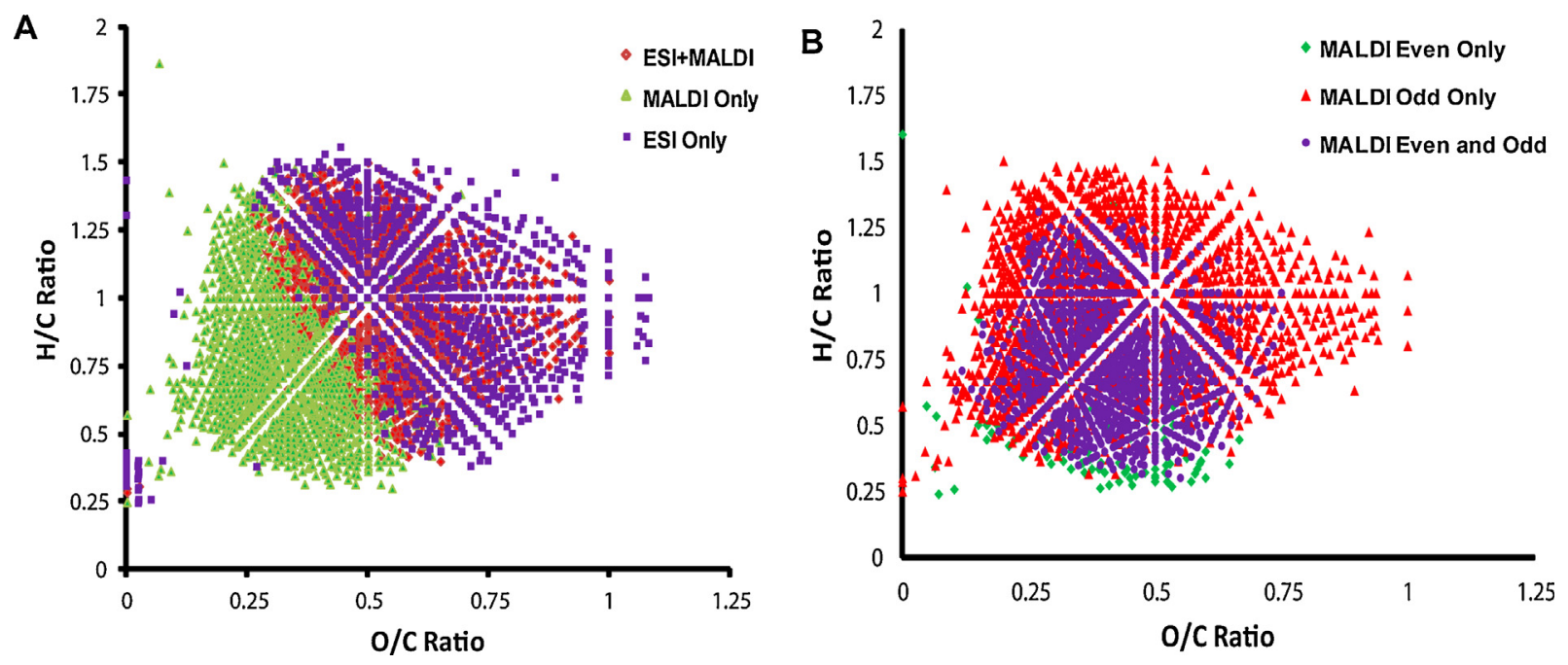

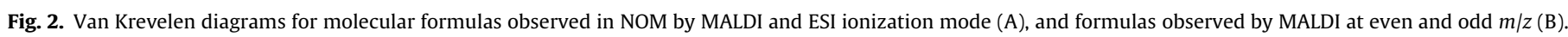


To further compare the selectivity of MALDI and ESI for NOM molecules, Van Krevelen diagrams were constructed for each formula by using the molar ratio of hydrogen to carbon ( $\mathrm{H} / \mathrm{C}$ ratio) as the ordinate and the molar oxygen to carbon ratio $(\mathrm{O} / \mathrm{C}$ ratio $)$ as the abscissa. Fig. 2A shows the Van Krevelen diagrams of the formulas observed by MALDI and ESI. A notable feature of selectivity of MALDI and ESI for NOM molecules was visually observed. In general, NOM molecules with relatively lower $\mathrm{O} / \mathrm{C}$ ratio $(\mathrm{O} / \mathrm{C}$ ratio $<0.5)$ were preferentially ionized by negative-ion MALDI, of which more than three-fourths of total numbers were not ionized by negative-ion ESI. However, those molecules with higher $\mathrm{O} / \mathrm{C}$ ratio $(\mathrm{O} / \mathrm{C}$ ratio $>0.5)$ were commonly ionized by MALDI and ESI or uniquely detected by ESI. Van Krevelen diagrams for molecular formulas observed by MALDI at even and odd $m / z$ peaks (Fig. 2B) suggested that NOM molecules with moderate $\mathrm{O} / \mathrm{C}$ ratio $(0.7>0 / C$ ratio $>0.25)$ and lower $\mathrm{H} / \mathrm{C}$ ratio were liable to form molecular anions during MALDI ionization process.
For purposes of visual resolution and identification of compound classes, types, and carbon distributions, plots of Kendrick mass defect vs. nominal Kendrick mass for mass spectral peaks detected by MALDI and ESI were constructed and shown in Figs. 3-5 and Figs. S1-S3 in the Supporting information. Kendrick mass (F) and Kendrick mass defect $(\mathrm{F})\left(\mathrm{F}=\mathrm{CH}_{2}, \mathrm{CO}, \mathrm{COO}, \mathrm{H}_{2} \mathrm{O}, \mathrm{H}_{2}, \mathrm{O}\right)$ were calculated according to previous reports [19,20]. Generally:

Kendrick mass $(F)=$ observed mass $\times[($ nominal mass of $F) /($ exact mass of F)]

Kendrick mass defect $(F)=($ nominal mass - Kendrick mass $(F))(2)$

Each of the plots showed that the relatively large molecules ( $800 \mathrm{Da}>\mathrm{MW}>600 \mathrm{Da}$ ) were preferentially ionized by the ESI mode relative to MALDI (Figs. S1A, S2A and S3A in the Supporting information, and Figs. 3A, 4A, 5A). The scale-expanded Kendrick
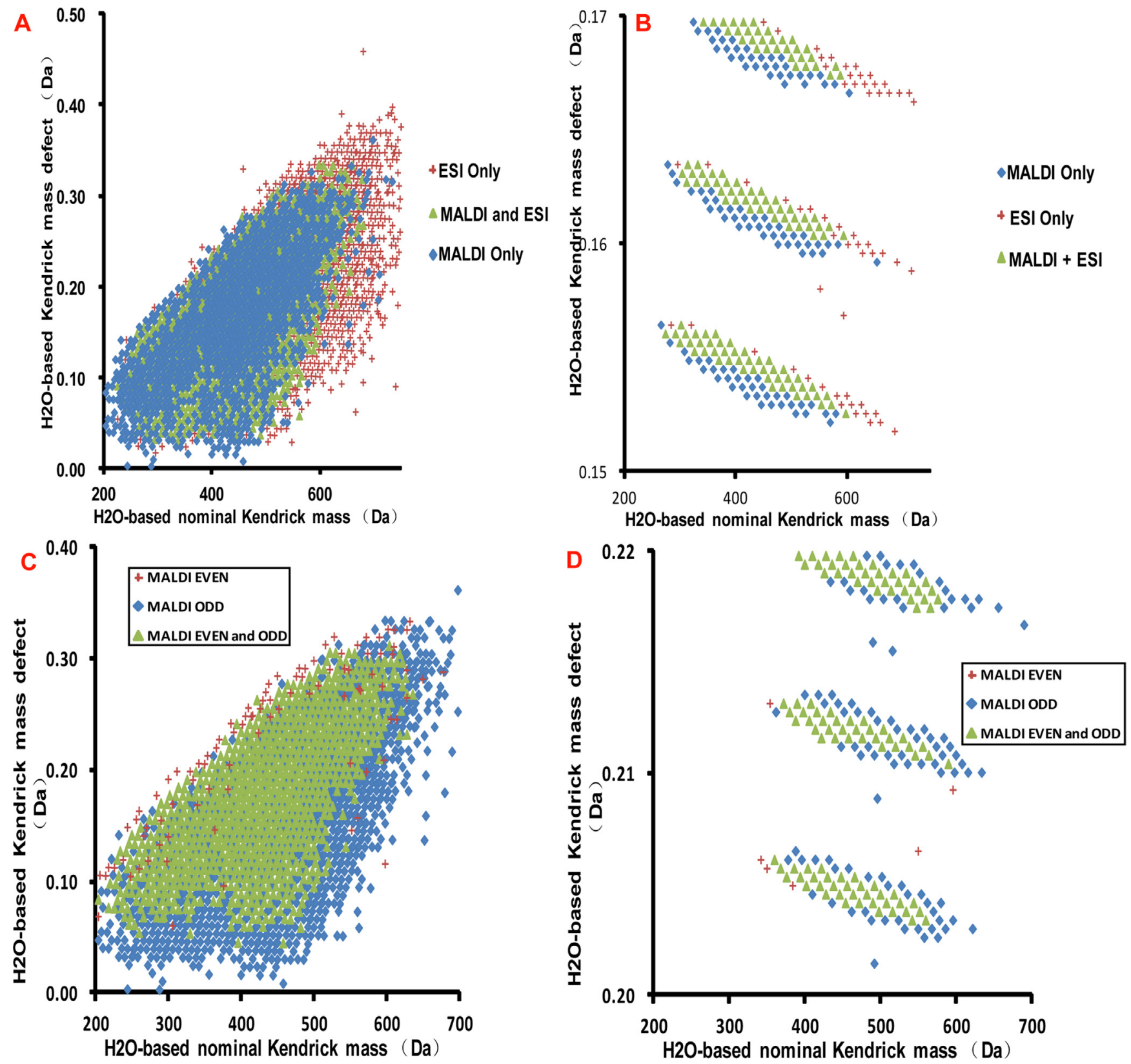

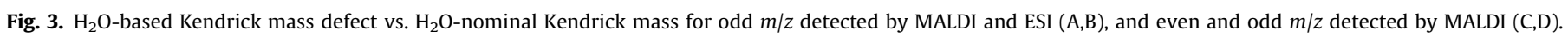




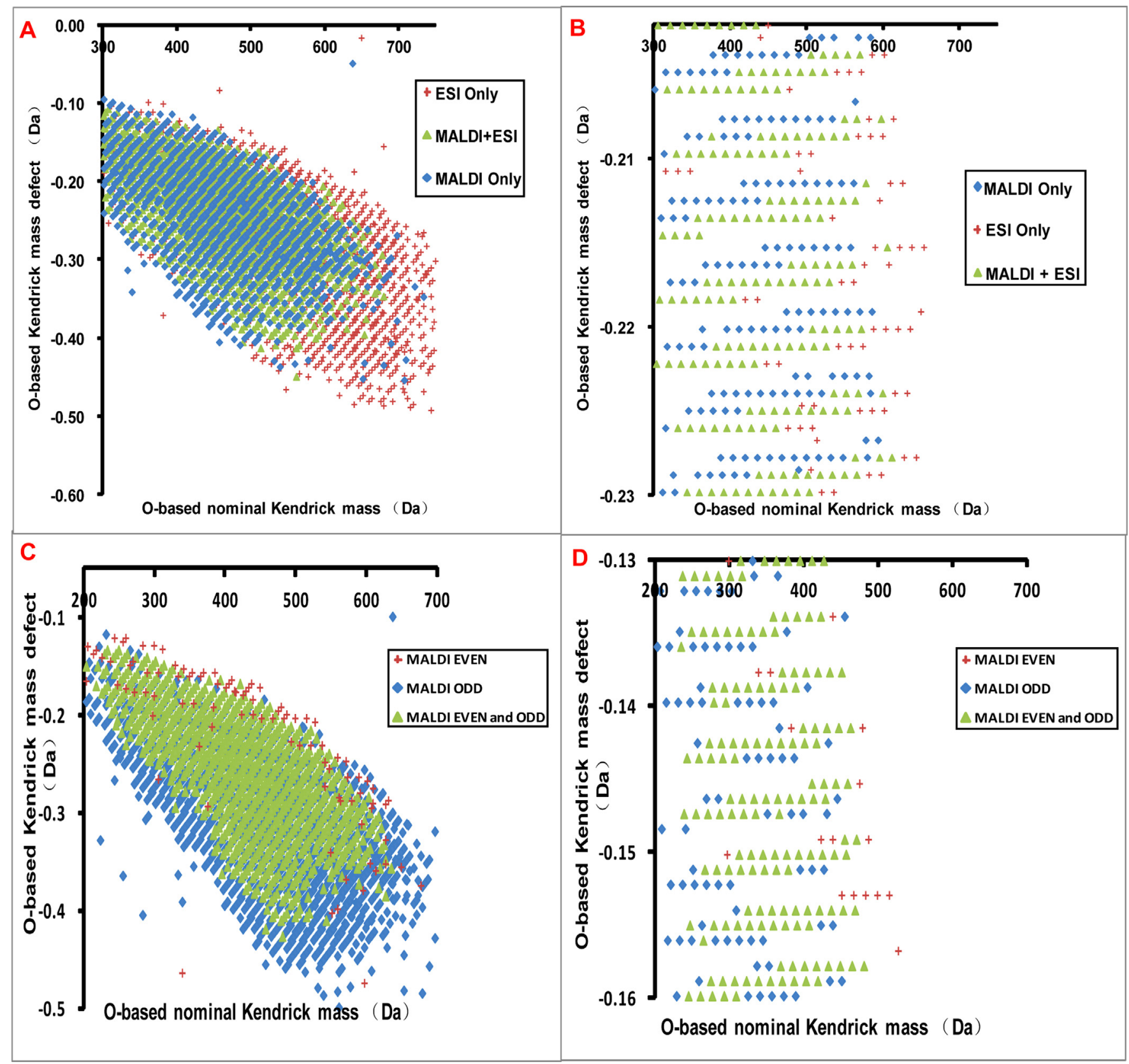

Fig. 4. O-based Kendrick mass defect vs. O-nominal Kendrick mass for odd $m / z$ detected by MALDI and ESI (A,B), and even and odd $m / z$ detected by MALDI (C,D).

mass defect or nominal Kendrick mass segments of plots revealed some remarkable features (Figs. S1B, S2B and S3B in the Supporting information, and Figs. 3B, $4 \mathrm{~B}, 5 \mathrm{~B}$ ). In the $\mathrm{CH}_{2^{-}}, \mathrm{CO}_{2^{-}}$or $\mathrm{H}_{2}$-based Kendrick mass plots (Figs. S1B and S2B in the Supporting information, and Fig. 5B), the results showed that some compounds of identical class are uniquely ionized by MALDI in negative mode, and alternation of the numbers of $\mathrm{CH}_{2^{-}}, \mathrm{CO}_{2^{-}}$or $\mathrm{H}_{2}$-groups had no effect on the ionization selectivity of MALDI for those compounds. By contrast, these plots do not show any compounds of identical class being uniquely ionized by ESI. We speculate that those compounds uniquely ionized by MALDI may be non-polar compounds, so they are more difficult to ionize by ESI, although polar portions of those compounds may be affected by the alternation of the number of $\mathrm{CH}_{2}$, $\mathrm{CO}_{2-}$ or $\mathrm{H}_{2}$-groups. Interestingly, in the CO-based Kendrick mass plots (Fig. S3B in the Supporting information), some compounds of identical class being uniquely ionized by ESI were also found, except those compounds of identical class uniquely ionized by MALDI. The more notable features were observed in the $\mathrm{H}_{2} \mathrm{O}$-based Kendrick mass plots (Fig. 3B). The plots show that the molecules within a class are more liable to be ionized by MALDI by decreasing the number of $\mathrm{H}_{2} \mathrm{O}$-groups. Conversely, by increasing the number of $\mathrm{H}_{2} \mathrm{O}$-groups, the molecules will be preferentially ionized by ESI. We speculate that the number of $\mathrm{H}_{2} \mathrm{O}$-groups may be related to the polarity of molecules. With increasing the number of $\mathrm{H}_{2} \mathrm{O}$-groups, the polarity of molecules will increase. So molecules with higher number of $\mathrm{H}_{2} \mathrm{O}-$ groups are more polarity, which lead them to being preferentially ionized by ESI, but those with lower number of $\mathrm{H}_{2} \mathrm{O}$-groups may be non-polar compounds which are liable to be ionized by MALDI. Similar trends are also observed in the O-based Kendrick mass plots (Fig. 4B). That is to say, identical classes of molecules with more Ogroups will be more likely to ionize by ESI, but those with fewer Ogroups will be preferentially ionized by MALDI. These remarkable observations further suggest that NOM molecules with lower $\mathrm{O} / \mathrm{C}$ ratio are more likely to be ionized by MALDI. 

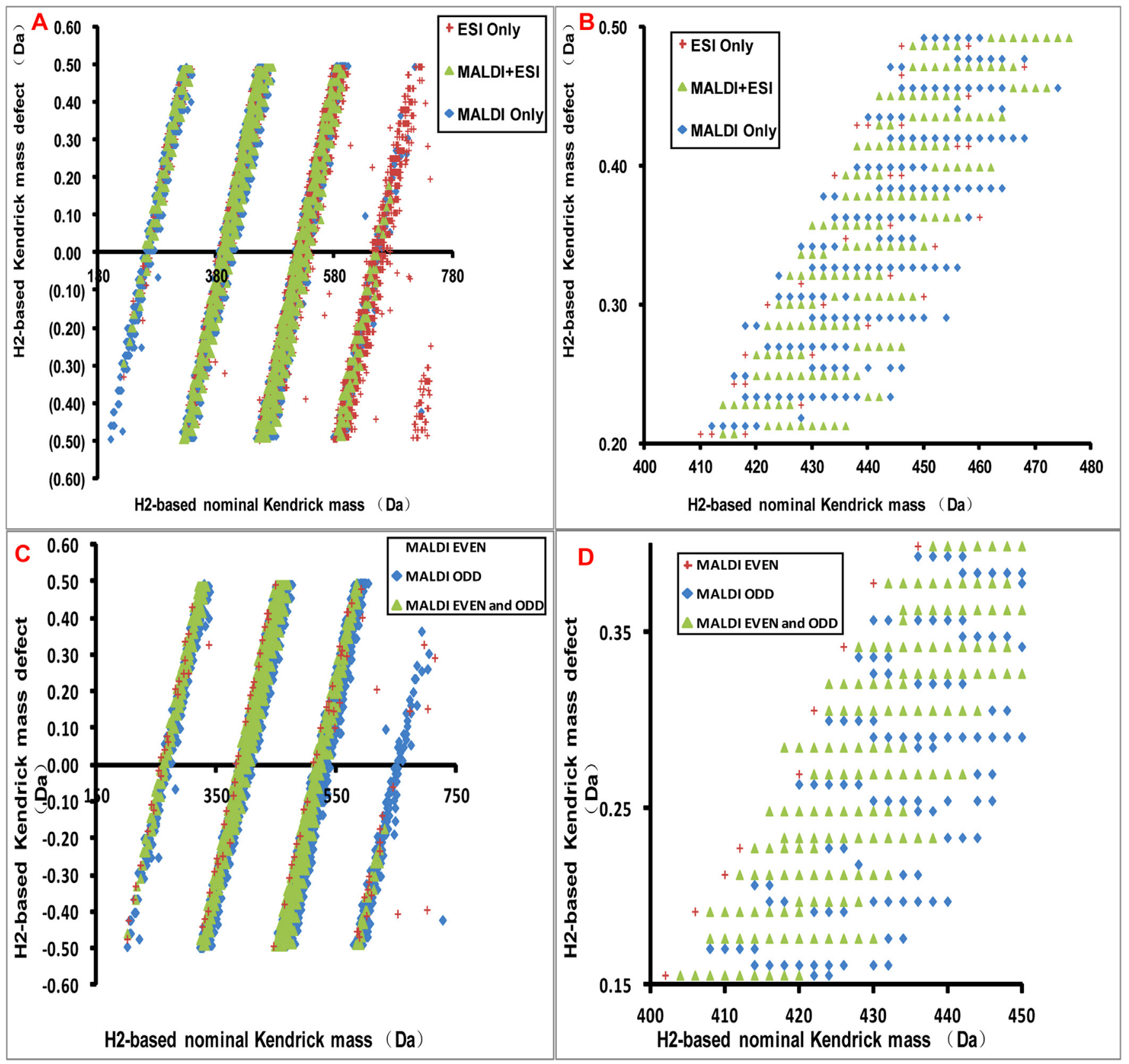

Fig. 5. $\mathrm{H}_{2}$-based Kendrick mass defect vs. $\mathrm{H}_{2}$-nominal Kendrick mass for odd $m / z$ detected by MALDI and ESI (A,B), and even and odd $m / z$ detected by MALDI (C,D).

Analysis of plots of Kendrick mass defect vs. nominal Kendrick mass for even- and odd-mass ions detected by MALDI (Figs. S1C and D, S2C and D, S3C and D in the Supporting information, and Figs. 3 C and D, 4C and D, 5C and D) shows that some compounds of identical class are uniquely observed at odd $\mathrm{m} / \mathrm{z}$ in MALDI mode, and alternation of the numbers of $\mathrm{CH}_{2-}, \mathrm{CO}_{2}$ - or $\mathrm{CO}$-groups cannot lead these molecules to form molecular ions at even $m / z$. However, in the plots of $\mathrm{H}_{2} \mathrm{O}$ - and $\mathrm{H}_{2}$-based Kendrick mass defect vs. nominal Kendrick mass (Figs. 3D, 5D), notable features were observed. Identical classes of molecules with more $\mathrm{H}_{2} \mathrm{O}$ - or $\mathrm{H}_{2}$-groups will be more likely to form deprotonated ions at odd $m / z$, but those with fewer $\mathrm{H}_{2} \mathrm{O}$ - or $\mathrm{H}_{2}$-groups will more readily form molecular ions at even $m / z$ by MALDI. This observation suggests that NOM molecules with higher $\mathrm{H} / \mathrm{C}$ ratio are more likely to form deprotonated ions at odd $m / z$, whereas those with lower $\mathrm{H} / \mathrm{C}$ ratio are more likely to form molecular ions at even $\mathrm{m} / \mathrm{z}$.
To estimate the aromatic and condensed aromatic structures of NOM ions detected by MALDI and ESI, a modified aromaticity index (AI_mod) was calculated from the formulas according to previous works $[9,18]$. For $\mathrm{C}_{n} \mathrm{H}_{m} \mathrm{O}_{q}$ compounds of NOM, AI_mod values are calculated as follows:

AI_mod $=(1+n-0.5 \times q-0.5 \times m) /(n-0.5 \times q)$

Aromatic and condensed aromatic structures can be identified with threshold criteria of AI_mod $>0.5$ and AI_mod $\geq 0.67$ (as shown in Fig. 6). For the molecules uniquely detected by MALDI (Fig. 6A), 76.3\% of them contain aromatic structures, including a large proportion of condensed aromatic structures (41.2\%). By contrast, for the molecules uniquely detected by ESI (Fig. 6B), only $23.7 \%$ of them involve aromatic structures, and of those, only a small proportion of condensed aromatic structures (9.6\%) are included. The compounds commonly detected by ESI and MALDI 


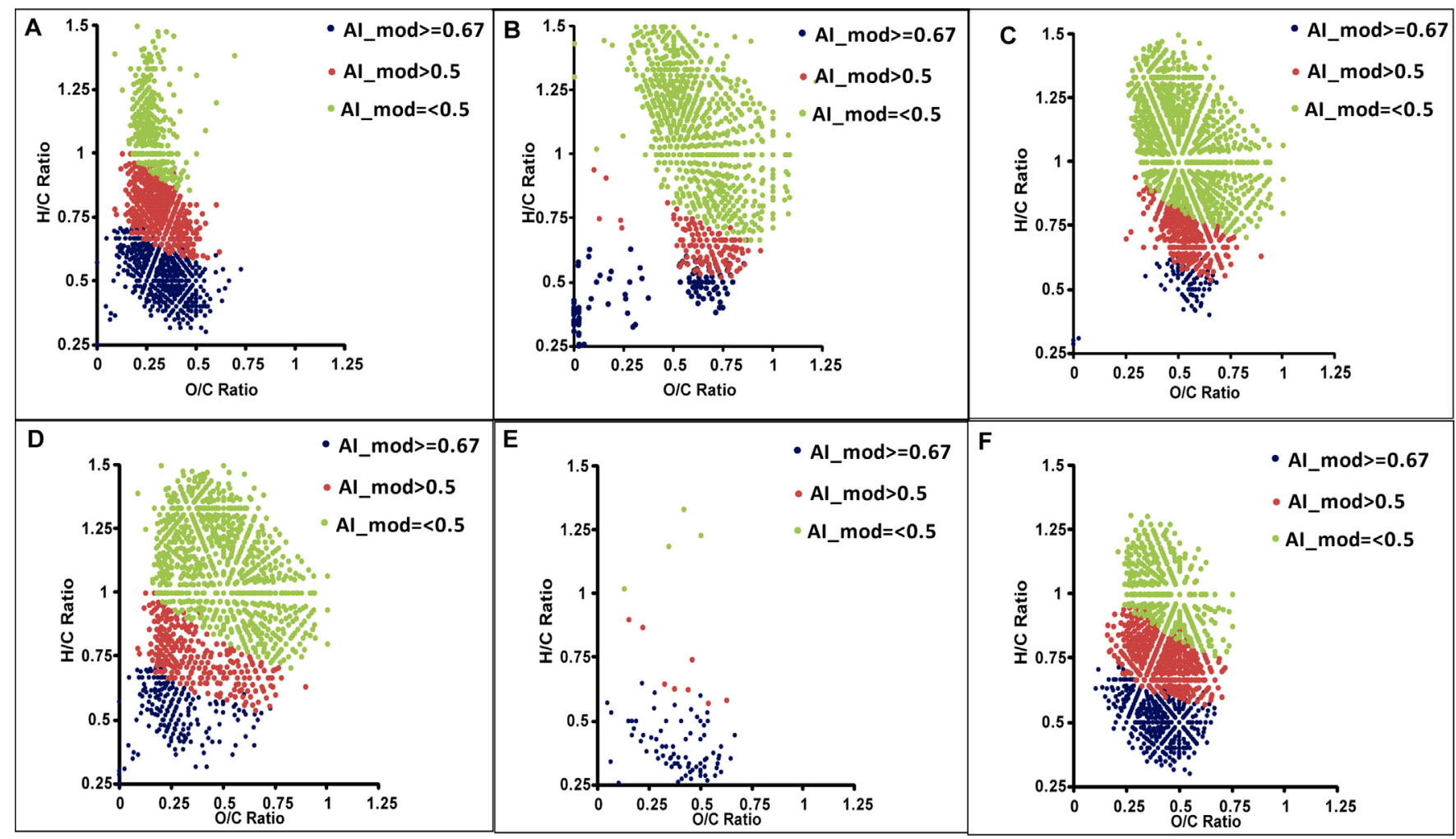

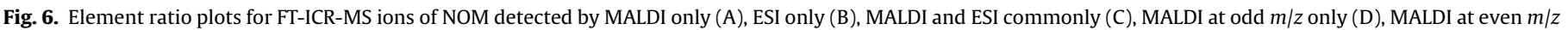

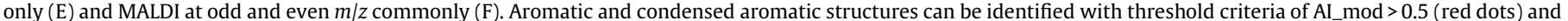
AI_mod $\geq 0.67$ (blue dots). (For interpretation of the references to color in the legend, the reader is referred to the web version of this article.)

show roughly similar trends with those uniquely detected by ESI (Fig. 6C). Another distinction for these aromatic molecules is that nearly all of the molecules uniquely detected by MALDI involving aromatic structures have low $\mathrm{O} / \mathrm{C}$ ratios $(\mathrm{O} / \mathrm{C}$ ratios $<0.5)$, but for those uniquely detected by ESI or commonly detected by ESI and MALDI, the majority of them have higher $\mathrm{O} / \mathrm{C}$ ratios $(1>\mathrm{O} / \mathrm{C}$ ratios $>0.5$ ). These observations suggest that aromatic and condensed aromatic compounds with low $\mathrm{O} / \mathrm{C}$ ratio $(\mathrm{O} / \mathrm{C}$ ratios $<0.5$ ) in NOM are preferentially ionized by MALDI but cannot be ionized by ESI. Only a small proportion of aromatic and condensed aromatic compounds with higher $\mathrm{O} / \mathrm{C}$ ratios $(1>0 / \mathrm{C}$ ratios $>0.5)$ can be ionized by ESI. We speculate that the aromatic structures can partly absorb laser energy and give rise to ion formation more easily during the MALDI ionization process. Furthermore, aromatic structures and lower $\mathrm{O} / \mathrm{C}$ ratio may lead the compounds to having lower polarity, both of which may lead those compounds with aromatic and condensed aromatic structures and low $\mathrm{O} / \mathrm{C}$ ratio $(\mathrm{O} /$ C ratios $<0.5$ ) to being difficult to ionize by ESI but uniquely ionized by MALDI.

For analysis of the molecules detected by MALDI at even and odd $m / z$ peaks, the elemental ratio plots are displayed in Fig. 6D-F. The plots reveal that of the molecules detected by MALDI at both odd and even peaks, $69.2 \%$ had AI_mod $>0.5$, that is, had aromatic or condensed aromatic structures (Fig. 6F). Furthermore, $97.9 \%$ of the molecules uniquely detected by MALDI at even $\mathrm{m} / \mathrm{z}$ peaks contain aromatic or condensed aromatic structures (as shown in Fig. 6E). This result suggests that most of the molecules of NOM with aromatic or condensed aromatic structures are liable to obtain electrons and form molecular anions in negative-ion MALDI.

Nominal oxidation state of carbon (NOSC), first introduced by Riedel et al. [9] as a formal parameter for interpretation of ultrahigh precision mass spectrometry data, can provide information on the average oxidation state of all carbons per standard calculations. Meanwhile, the parameter can also give an indirect measure for the polarity of a compound. For $\mathrm{C}_{n} \mathrm{H}_{m} \mathrm{O}_{q}$ compounds of NOM, NOSC can be estimated from the chemical formula using the following equation:

NOSC $=4-[(4 n+m-2 q) / n]$

To further investigate whether the oxygen content or the degree of unsaturation of molecules in NOM is responsible for the ionizing selectivities of MALDI and ESI, plots of DBE vs. NOSC were constructed and shown in Fig. 7. Based on these plots, it is apparent that molecules with the highest NOSC values are detected primarily only by ESI, which suggests that ESI shows an ionizing preference for more oxygenated molecules with greater polarity (see Fig. 7A). Conversely, most of molecules with lower NOSC values but higher DBE values can only be detected by MALDI. This indicates that less oxygenated and more unsaturated molecules are more liable to be ionized by MALDI. These results agree well with our expectation. In the plot of DBE vs. NOSC for formulas observed by MALDI at even and odd $m / z$ peaks (Fig. 7B), molecules with identical DBE values but with higher NOSC values are seen to be liable to form molecular anions at even $\mathrm{m} / \mathrm{z}$. It suggests that more oxygenated analytes may be more likely to contain special substituent groups which are preferential to form free radical anions by obtaining electrons during MALDI ionization. Furthermore, with the values of DBE increasing, the number of molecules which can form molecular anions increases gradually. This suggests that molecules with a higher degree of unsaturation are more likely to form molecular anions. As the degree of unsaturation increases, the aromaticity may also increase. So we can speculate that molecules with more aromaticity are liable to form molecular anions. AI_mod plots as shown in Fig. 6D-F demonstrate this trend. 

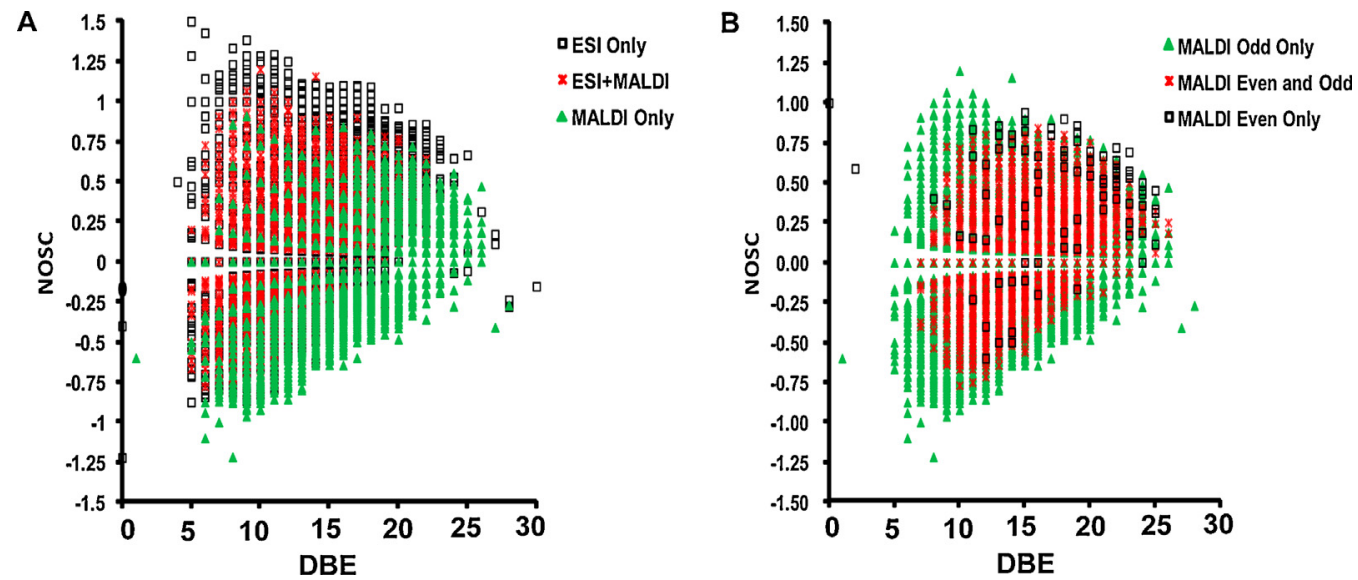

Fig. 7. Plots of DBE vs. the average nominal oxidation state of carbon (NOSC) in each formula observed by MALDI and ESI (A) and by MALDI at even and odd $m / z$ (B).

\section{Conclusions}

NOM is so complex that multiple ionization methods should be combined to gain more comprehensive molecular information of NOM, because different ionization methods, such as ESI, APCI, APPI and MALDI, have different ionizing selectivities for NOM molecules with different properties (such as polarity and aromaticity). In this study, MALDI coupled with FT-ICR-MS was first employed for characterization of NOM within a mass range of 200-800 Da in molecular level. Furthermore, the obtained mass spectral data by MALDI were fully compared with data generated by ESI. Significant ionization selectivities of MALDI and ESI for different NOM molecules were observed. As expected, complementary molecular information about NOM that ESI cannot detect was provided by MALDI. It is notable that more unsaturated and aromatic constituents of NOM with lower $\mathrm{O} / \mathrm{C}$ ratio $(\mathrm{O} / \mathrm{C}$ ratio $<0.5)$ are preferentially ionized in MALDI negative mode, whereas polar constituents of NOM with higher $\mathrm{O} / \mathrm{C}$ ratio are preferentially ionized in ESI negative mode. The ionization selectivities of MALDI and ESI mainly attribute to the difference of ionization mechanism of these two techniques. The principles of ionization with ESI and MALDI have been well reviewed by Cole [29], Zenobi and Knochenmuss [28] and Dreisewerd [30] separately. In general, ESI ionizes molecules by transferring pre-existing ions from solution phase to gas phase. Therefore, molecules that exist as ions in solution or those with acidic or basic groups capable of forming deprotonated or protonated ions are liable to ionize by ESI, Whereas, MALDI ion formation includes a number of chemical and physical pathways, such as gas-phase photoionization, excitedstate proton transfer, thermal ionization, and desorption of preformed ions. Thus, molecules with unsaturated or aromatic core structures which are liable to absorb UV laser energy are preferentially ionized by MALDI. Moreover, most of the molecular anions that appeared at even $m / z$ in MALDI negative ion mode were analyzed. The analysis of those molecules indicated that molecules of NOM with Lower $\mathrm{H} / \mathrm{C}$ ratios and moderate $\mathrm{O} / \mathrm{C}$ ratios $(0.7>0 / \mathrm{C}$ ratio $>0.25$ ) as well as containing aromatic or condensed aromatic structures are liable to form molecular anions during MALDI ionization. In summary, it is notably demonstrated that MALDI is another useful ionization method for providing more complementary molecular information about NOM. For purposes of comprehensive characterization of NOM at the molecular level, more than one ionization methods should be applied.

\section{Conflict of interest}

The authors declare no competing financial interest.

\section{Acknowledgments}

This work was supported by the National Basic Research Program of China (2014CB441102) and the National Natural Science Foundation of China (Grant Nos. 21477140, 21107130, and 21007079).

\section{Appendix A. Supplementary data}

Supplementary data associated with this article can be found, in the online version, at http://dx.doi.org/10.1016/j.aca.2015.01.051.

\section{References}

[1] X. Yang, C. Jiang, H. Hsu-Kim, A.R. Badireddy, M. Dykstra, M. Wiesner, D.E. Hinton, J.N. Meyer, Silver nanoparticle behavior, uptake, and toxicity in Caenorhabditis elegans: effects of natural organic matter, Environ. Sci. Technol. 48 (2014) 3486-3495.

[2] J.P. Gustafsson, I. Persson, A.G. Oromieh, J.W. van Schaik, C. Sjöstedt, D.B. Kleja, Chromium(III) complexation to natural organic matter: mechanisms and modeling, Environ. Sci. Technol. 48 (2014) 1753-1761.

[3] B.A. Lyon, R.Y. Milsk, A.B. DeAngelo, J.E. Simmons, M.P. Moyer, H.S. Weinberg, Integrated chemical and toxicological investigation of UV-chlorine/ chloramine drinking water treatment, Environ. Sci. Technol. 48 (2014) 6743-6753.

[4] E.E. Lavonen, M. Gonsior, L.J. Tranvik, P. Schmitt-Kopplin, S.J. Köhler, Selective chlorination of natural organic matter: identification of previously unknown disinfection byproducts, Environ. Sci. Technol. 47 (2013) 2264-2271.

[5] A.C. Stenson, W.M. Landing, A.G. Marshall, W.T. Cooper, Ionization and fragmentation of humic substances in electrospray ionization Fourier transform ion cyclotron resonance mass spectrometry, Anal. Chem. 74 (2002) 4397-4409.

[6] T. Reemtsma, T. Anja, A. Springer, M. Linscheid, Fulvic acids as transition state of organic matter: indications from high resolution mass spectrometry, Environ. Sci. Technol. 40 (2006) 5839-5845.

[7] A.C. Stenson, A.G. Marshall, W.T. Cooper, Exact masses and chemical formulas of individual Suwannee River fulvic acids from ultrahigh resolution electrospray ionization Fourier transform ion cyclotron resonance mass spectrometry, Anal. Chem. 75 (2003) 1275-1284.

[8] N. Hertkorn, M. Frommberger, M. Witt, B.P. Koch, Ph. Schmitt-Kopplin, E.M. Perdue, Natural organic matter and the event horizon of mass spectrometry, Anal. Chem. 80 (2008) 8908-8919.

[9] T. Riedel, H. Biester, T. Dittmar, Molecular fractionation of dissolved organic matter with metal salts, Environ. Sci. Technol. 46 (2012) 4419-4426.

[10] E.B. Kujawinski, R. Del Vecchio, N.V. Blough, G.C. Klein, A.G. Marshall, Probing molecular-level transformations of dissolved organic matter: insights from electrospray ionization Fourier transform ion cyclotron resonance mass spectrometry, Mar. Chem. 92 (2004) 23-37.

[11] K. Mopper, A. Stubbins, J.D. Ritchie, H.M. Bialk, P.G. Hatcher, Advanced instrumental approaches for characterization of marine dissolved organic matter: extraction techniques, mass spectrometry, and nuclear magnetic resonance spectroscopy, Chem. Rev. 107 (2007) 419-442.

[12] J. D'Andrilli, T. Dittmar, B.P. Koch, J.M. Purcell, A.G. Marshall, W.T. Cooper, Comprehensive characterization of marine dissolved organic matter by Fourier transform ion cyclotron resonance mass spectrometry with electrospray and atmospheric pressure photoionization, Rapid Commun. Mass Spectrom. 24 (2010) 643-650. 
[13] W.C. Hockaday, J.M. Purcell, A.G. Marshall, J.A. Baldock, P.G. Hatcher, Electrospray and photoionization mass spectrometry for the characterization of organic matter in natural waters: a qualitative assessment, Limnol. Oceanogr. Methods 7 (2009) 81-95.

[14] A. Fievre, T. Solouki, A.G. Marshall, W.T. Cooper, High-resolution Fourier transform ion cyclotron resonance mass spectrometry of humic and fulvic acids by laser desorption/ionization and electrospray ionization, Energy Fuels 11 (1997) 554-560.

[15] R.Q. Wang, K. Druckenmüller, G.E. Klaus Guentherd, J.P. Crouéb, Analysis of aquatic-phase natural organic matter by optimized LDI-MS method, J. Mass Spectrom. 49 (2014) 154-160.

[16] W. Haberhauer, E. Bednar, M.H. Rosenberg, Application of MALDI-TOF-MS to the characterization of fulvic acids, in: G. Davis, E. Ghabbour (Eds.), Humic Substances: Versatile Components of Plants, Soil and Water, 59, Special Publication of the Royal Society of Chemistry, London, 2000, pp. 143-152.

[17] M.S. Mugo, C.S. Bottaro, Characterization of humic substances by matrixassisted laser desorption/ionization time-of-flight mass spectrometry, Rapid Commun. Mass Spectrom. 18 (2004) 2375-2382.

[18] B.P. Koch, T. Dittmar, From mass to structure: an aromaticity index for highresolution mass data of natural organic matter, Rapid Commun. Mass Spectrom. 20 (2006) 926-932.

[19] S. Kim, R.W. Kramer, P.G. Hatcher, Graphical method for analysis of ultrahighresolution broadband mass spectra of natural organic matter, the Van Krevelen diagram, Anal. Chem. 75 (2003) 5336-5344.

[20] C.A. Hughey, C.L. Hendrickson, R.P. Rodgers, A.G. Marshall, Kendrick mass defect spectrum: a compact visual analysis for ultrahigh-resolution broadband mass spectra, Anal. Chem. 73 (2001) 4676-4681.

[21] R.W. Alder, P.S. Bowman, W.R.S. Steele, D.R. Winterman, The remarkable basicity of 1,8-bis(dimethylamino) naphthalene, J. Chem. Soc. Chem. Commun. 13 (1968) 723-726.
[22] R. Shroff, A. Svatoŏs, 1,8-Bis(dimethylamino) naphthalene: a novel superbasic matrix for matrix-assisted laser desorption/ionization time-of-flight mass spectrometric analysis of fatty acids, Rapid. Commun. Mass Spectrom. 23 (2009) 2380-2382.

[23] R. Shroff, L. Rulísek, J. Doubsk'y, A. Svatoŏs, Acid-base-driven matrix-assisted mass spectrometry for targeted metabolomics, Proc. Natl. Acad. Sci. U. S. A. 106 (2009) 10092-10096.

[24] D. Cao, Z.D. Wang, C.G. Han, L. Cui, M. Hu, J.J. Wu, Y.X. Liu, Y.Q. Cai, H.L. Wang, Y. H. Kang, Quantitative detection of trace perfluorinated compounds in environmental water samples by matrix-assisted laser desorption/ ionization-time of flight mass spectrometry with 1,8-bis (tetramethylguanidino)-naphthalene as matrix, Talanta 85 (2011) 345-352.

[25] D. Cao, M. Hu, C. Han, J. Yu, L. Cui, Y. Liu, H. Wang, Y. Cai, Y. Kang, Y. Zhou, Proton sponge-functionalized silica as high performance adsorbents for solid-phase extraction of trace perfluoroalkyl sulfonates in the environmental water samples and their direct analysis by MALDI-TOF-MS, Analyst 137 (2012) 22182225.

[26] E.B. Kujawinski, P.G. Hatcher, M.A. Freitas, High-resolution Fourier transform ion cyclotron resonance mass spectrometry (FT-ICR MS) of humic and fulvic acids: improvements and comparisons, Anal. Chem. 74 (2002) 413-419.

[27] E.B. Kujawinski, M.D. Behn, Automated analysis of electrospray ionization Fourier transform ion cyclotron resonance mass spectra of natural organic matter, Anal. Chem. 78 (2006) 4363-4373.

[28] R. Zenobi, R. Knochenmuss, Ion formation in MALDI mass spectrometry, Mass Spectrom. Rev. 17 (1998) 337-366.

[29] R.B. Cole, Some tenets pertaining to electrospray ionization mass spectrometry, J. Mass Spectrom. 35 (2000) 763-772.

[30] K. Dreisewerd, The desorption process in MALDI, Chem. Rev. 103 (2003) 395-425. 